\title{
Closed Fracture of Ribs, Multiple Sites
}

National Cancer Institute

\section{Source}

National Cancer Institute. Closed Fracture of Ribs, Multiple Sites. NCI Thesaurus. Code C35230.

A traumatic break in two or more places in one rib, or a traumatic break in more than one rib, that does not involve a break in the adjacent skin. 